\title{
THE ADVANCED PHOTON SOURCE LINAC MODULATORS PSPICE SIMULATION AND UPGRADE*
}

\author{
A. Cours ${ }^{\xi}$, T. Smith \\ Argonne National Laboratory, 9700 S. Cass Ave. \\ Argonne, Illinois, 60439, USA
}

\section{Abstract}

The APS linac modulators provide DC pulses to Thales 35/45-MW klystrons. The modulators are pulse forming network (PFN)-type pulsers with EMI 40-kV switch-mode charging supplies. The PFN consists of two 8-cell lines connected in parallel. EEV CX1836A thyratrons are used as discharge switches.

The PSpice simulation of the modulators using OrCAD release 9.1 made it possible to find appropriate parameters of RC circuits that reduce high-frequency ringing of the pulse transformer primary voltage.

In order to improve pulse top flatness (originally $\pm 3 \%$ ), new coils were built and installed. The coils allow discrete tuning of pulse waveforms by changing the amount of used turns. The advantage of two parallel-line PFN configurations was also used. An equivalent method using a low-voltage generator was used for PFN fine tuning.

\section{THE MODULATOR CIRCUITRY}

The modulator power circuitry is shown in Fig. 1.

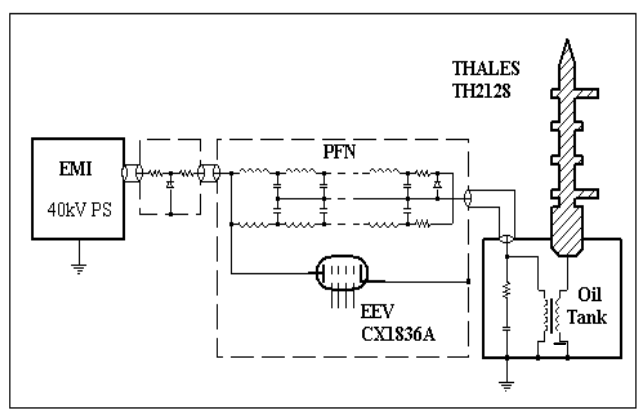

Figure 1. Modulator power circuitry.

\footnotetext{
* Work supported by U.S. Department of Energy, Office of Basic Energy Sciences, under Contract No. W-31-109ENG-38.

รemail: cours@aps.anl.gov
}

The main elements are $30 \mathrm{~kJ} / \mathrm{s}$ EMI power supply, 2×8-cell PFN, EEV thyratron switch, and 15.2:1 step-up pulse transformer (PT). In operation, the charging supply charges the PFN capacitors to up to $40 \mathrm{kV}$ and then the thyratron switch discharges the PFN into the matched 4- $\Omega$ reflected load of the klystron cathode. The process then repeats at a 30 p.p.s. rate. The modulator has a fairly standard design and has been presented at various particle accelerator conferences $[1,2]$.

\section{MAIN PARAMETERS}

The modulators' main parameters are listed in Table 1. The parameters reflect the current status of the modulators after upgrade and fine PFN tuning.

Table 1. Modulator main parameters.

\begin{tabular}{|ll|}
\hline \multicolumn{1}{|c|}{ Name } & \multicolumn{1}{c|}{ Value } \\
PFN Voltage, Max & $40 \mathrm{kV}$ \\
Regulation & $0.15 \%$ \\
PFN Impedance & $3.8 \Omega$ \\
Pulse Width & $5 \mu \mathrm{s}$ \\
Rise Time & $0.7 \mu \mathrm{s}$ \\
Pulse Repetition Rate & $30 \mathrm{p} . \mathrm{p.s}$. \\
Peak Output Voltage & $300 \mathrm{kV}$ \\
Peak Output Current & $320 \mathrm{Amps}$ \\
Peak Output Power & $96 \mathrm{MW}$ \\
Average Output Power & $14 \mathrm{~kW}$ \\
Flat top & $3.5 \mu \mathrm{s}$ \\
Flatness & $\pm 0.5 \%$ \\
\hline
\end{tabular}

\section{PROBLEMS}

\section{A. High-Frequency Ringing}

High-frequency $(20-30 \mathrm{MHz})$ ringing of the pulse transformer primary voltage (Fig. 2) was the first problem found shortly after the modulators were built in 1993. A result of resonant oscillation between the PFN inductors and the modulators' stray capacitance, the ringing created significant excessive stress (peak value of the primary 
voltage reached as high as $200 \%$ of normal level) for various elements, especially high-voltage cables, which noticeably reduced cable lifetime.

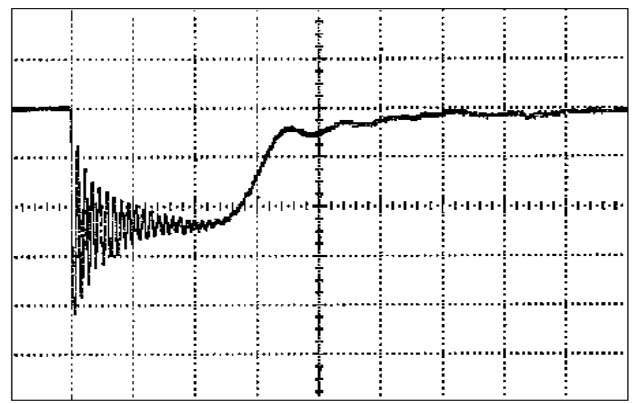

Figure 2. PT primary voltage ringing before upgrade.

\section{B. Voltage Drop}

Even though all cells of the PFN had the same parameters, voltage drop at the PT secondary voltage reached $6 \%$ over the shorter than 3.5- $\mu$ s flat part (Fig. 3). Until recently we could accept this, but some of the new applications of the linac require narrower energy spread of accelerated particles and, in turn, much flatter modulator pulses.

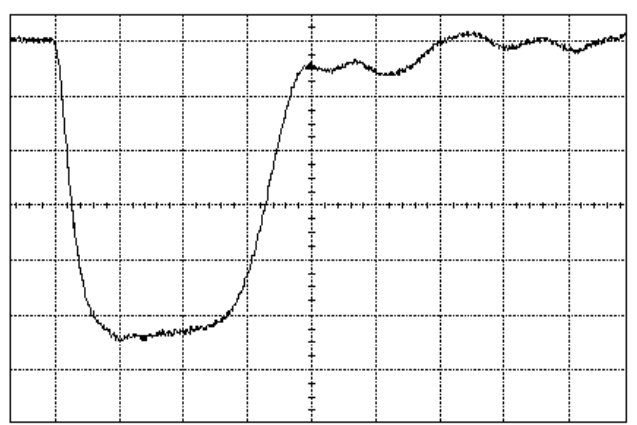

Figure 3. The PT secondary voltage before upgrade.

\section{SIMULATION}

\section{A. Nonfiltered Model}

In order to solve the problem mentioned above, a simple PSpice model of the modulators was built (Fig. 4) using OrCAD software.

The model contains all PFN cells, end of line (EOL) clipper, leakage inductance of the PT, resistive load representing reflected klystron impedance, a simple switch instead of the thyratron, and capacitor "Cstray" which represents the sum of all stray capacitances. The capacitor was placed at this particular point of the model because we believe that the output cables provide the main contribution to total stray capacitance.

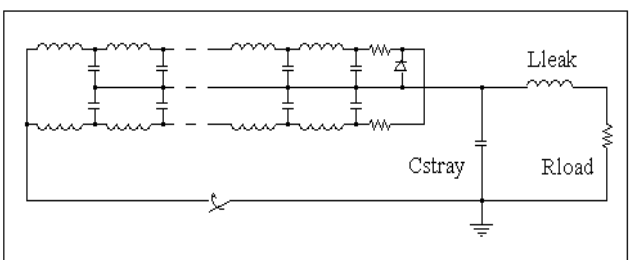

Figure 4. Nonfiltered PSpice model.

Simulation results for PT primary voltage are presented in Fig. 5. By finding proper values of stray capacitance and resistive loses of the model elements, the simulated and real (measured) waveforms of the primary pulses were almost identical.

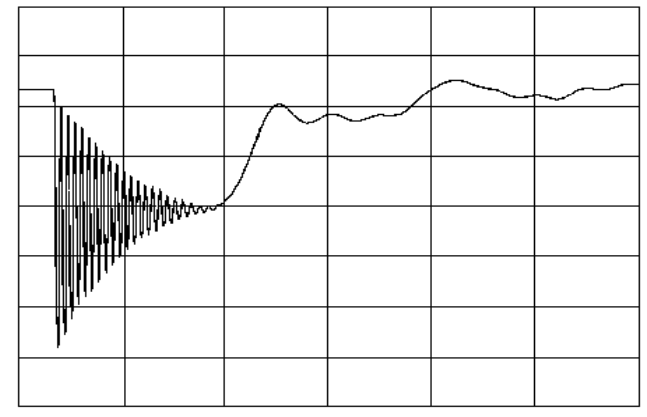

Figure 5. PSpice simulation of the PT primary voltage.

\section{B. Filtered Model}

In order to eliminate the high-frequency ringing, an RC filter circuit was added to the model (Fig. 6). We found that when the filter resistor and capacitor have values of $25 \Omega$ and $12 \mathrm{nF}$, respectively, the ringing disappeared completely (Fig. 7).

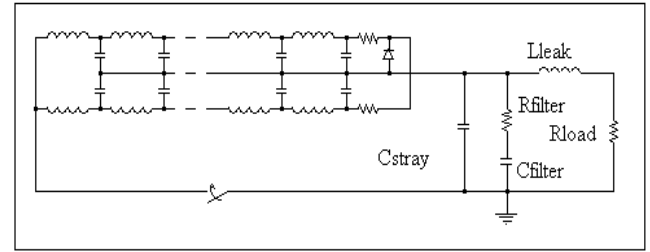

Figure 6. PSpice model with the RC filter circuit. 


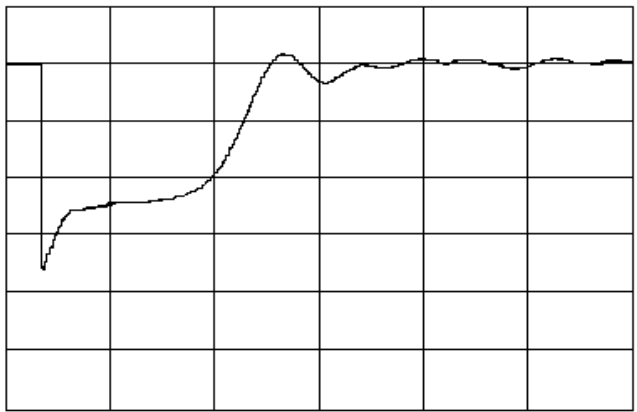

Figure 7. PSpice simulation of filtered PT primary voltage.

Based on the simulation results, a real filter circuit was built and installed into the PT oil tank. The circuit consists of two $50-\Omega, 200-\mathrm{W}$ resistors connected in parallel and five 2.5-nF capacitors. Figure 8 shows the real PT primary voltage plot that was taken after the filter was installed.

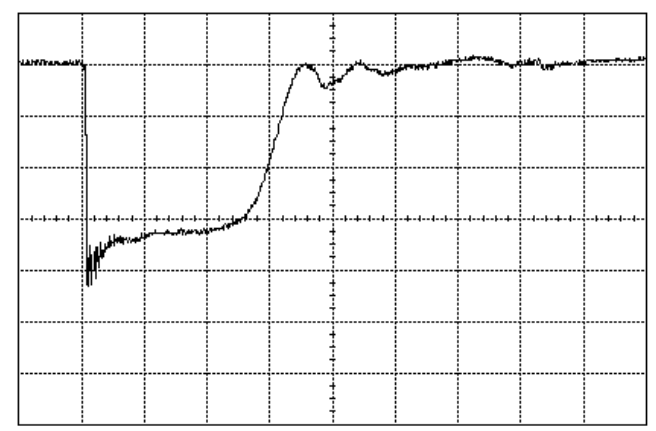

Figure 8. PT primary voltage with installed RC filter.

Simulated PT secondary voltage is presented in Fig. 9, which shows a very small difference between the simulated pulse and real pulse (Fig. 3).

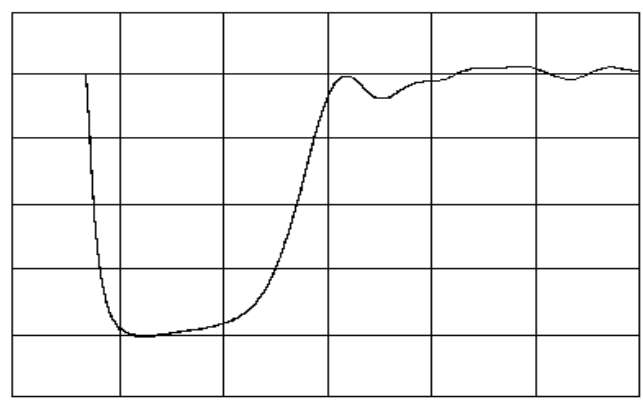

Figure 9. PSpice simulation of the PT secondary voltage with the RC filter on the primary side.

\section{PFN UPGRADE}

In order to improve pulse top flatness (originally $\pm 3 \%$ ), new coils were built and installed. The coils were made of $3 / 8^{\prime \prime}$ copper pipe (versus $1 / 4$ " for old coils) and contained more turns (Fig. 10).

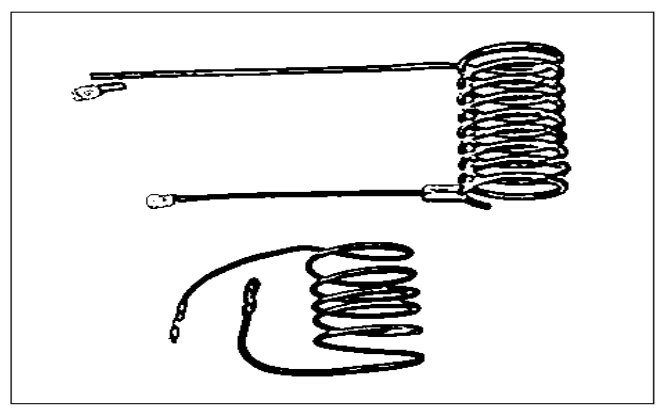

Figure 10. The new (top) and old (bottom) PFN coils.

Unlike the old coils, the new coil has only one permanent crimp lug. The second end of the coil remains unterminated. A specially designed tab can be connected to any turn of the coil if needed. Therefore, inductance of the coil can be adjusted for several different values. The new coils were installed and tuned in all modulators.

\section{PFN FINE TUNING}

\section{A. The Equivalent Generator Method}

The main problems with PFN tuning are maintaining high voltage and ensuring safety without being able to remotely control the coils. Figure 11 shows "The equivalent generator low voltage tuning method," a technique that was used for safety reasons.

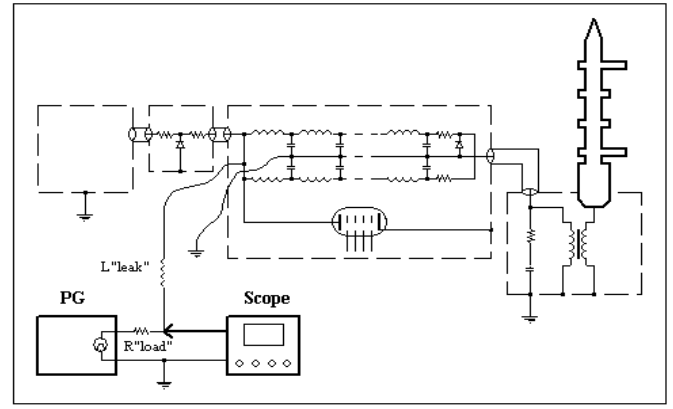

Figure 11. PFN tuning block diagram.

This method is based on the symmetry of charging and discharging processes in linear circuits. To embody the method we used a low-impedance pulse generator (PG), a digital scope, a $4-\Omega$ resistor that was used as the PFN load (R "load"), and a few- $\mu \mathrm{H}$ inductance as a replacement for the PT leakage inductance (L "leak"). 
Square, $25-\mathrm{V}, 50-\mu \mathrm{s}, 1-\mathrm{kHz}$ pulses from the PG initiated charge/discharge processes in the PFN. Before that, the modulator was turned off completely, all power sources were locked out, and the PFN cabinet was opened and checked for any possible remains of stored energy.

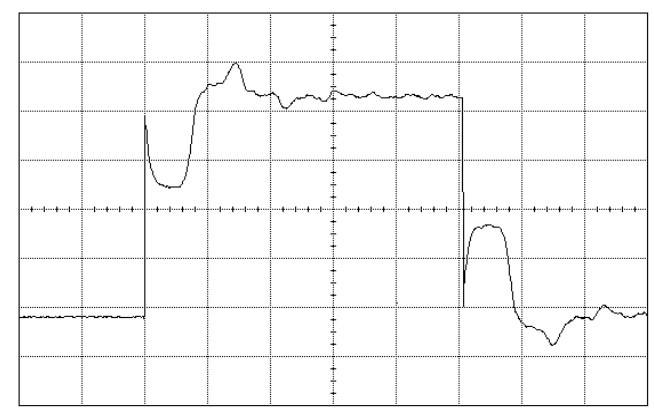

Figure 12. Voltage across R "load."

As can be seen in Fig. 12, the voltage across $\mathrm{R}$ "load" contains two images of the output pulse. The values of $R$ "load" and L "leak" are choosen so the low-level image more closely represents the high-level pulse waveform (Fig. 13). Either of the two images can be used during the tuning.

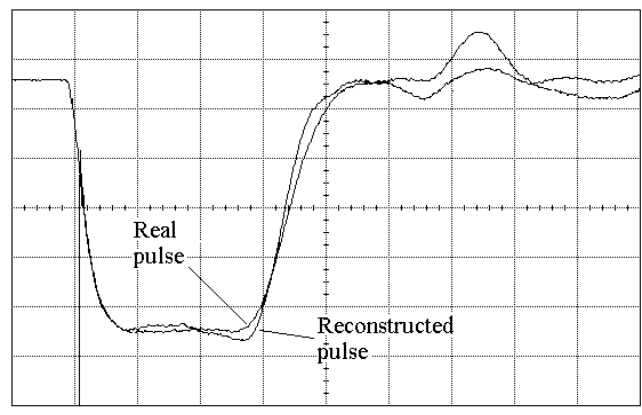

Figure 13. Real and "reconstructed" output pulses.

\section{B. The Tuning Process}

The process of tuning usually requires some time depending on exactness of the pulse reconstruction. Usually two or three intermediate high-voltage pulse form checks were performed.

During the tuning, flexible jumpers with "alligator" clamps were used for convenience. The existence of two 8-cell PFN parts connected in parallel made our discrete coil adjustment look smoother, since usually only one of every two parallel coils was changed. A slight imbalance of the two parts of the PFN has not caused any noticeable problems.

\section{Results}

A large-scale plot of the top of the output pulse after the PFN fine-tuning is shown in Fig. 14.

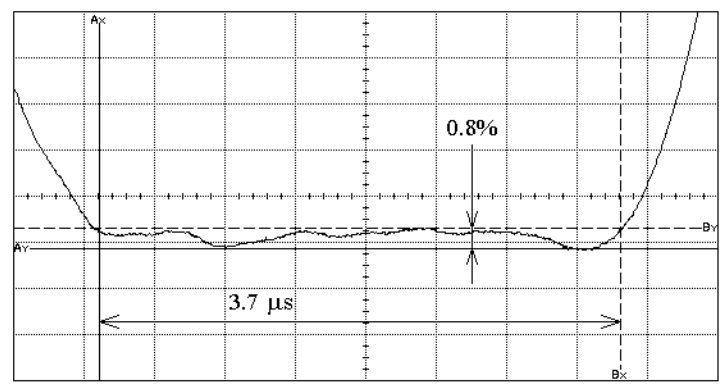

Figure 14. Final view of the output pulse's flat top.

\section{SUMMARY}

It was demonstrated that a very simple PSpice model of the modulators could help solve serious problems like high-frequency ringing of the pulse transformer primary voltage.

Also, a safe and simple method was used to adjust the high-voltage modulators' pulse forming network.

\section{ACKNOWLEDGEMENTS}

The authors wish to thank Dave Meyer and Tim Jonasson (RF Group) for their work on the modulator upgrade.

\section{REFERENCES}

[1] T. J. Russell, A. Cours, "Klystron Modulator Operation and Upgrades for the APS Linac," Proc. 1995 Particle Accelerator Conference, p. 1559, 1995.

[2] R. Fuja et al., "Constant-Current Charging Supplies for the Advanced Photon Source (APS) Linear Accelerator Modulators," Proc. 1997 Particle Accelerator Conference, p. 1269-1271, 1998.

The submitted manuscript has been created by the University of Chicago as Operator of Argonne National Laboratory ("Argonne") under Contract No. W-31-109-ENG-38 with the U.S. Department of Energy. The U.S. Government retains for itself, and others acting on its behalf, a paid-up, nonexclusive, irrevocable worldwide license in said article to reproduce, prepare derivative works, distribute copies to the public, and perform publicly and display publicly, by or on behalf of the Government. 